19 Crawshaw, L. I., Comp. Biochem. Physiol., 51A, 11-14 (1975).

20 Neill, W. H., and Magnuson, J. J., Trans. Am. Fish. Soc., 103, $663-710$ (1974). 21 Beitinger, T. L., Fish. Bull. Mass., 72, 1087-1093 (1974).

Neill, W. H., Magnuson, J. J., and Chipman, G. D., Science, 176, 1443-1445 (1972).

\section{Gravity as the sole navigational aid to the newborn quokka}

Alithough there is general agreement on the sequence of events at birth for several marsupial species', it is still not known how the newborn joey navigates on its journey from the mother's cloaca to her pouch. Frith and Calaby ${ }^{2}$ have postulated that, at birth, the red kangaroo (Megaleia rufa) ". . . has large nostrils and presumably a well developed sense of smell which probably plays a major part in its location of the pouch". On the other hand, Hartman $^{3}$ has suggested that the newborn opossum (Didelphis virginiana) was "negatively geotropic" though he has now modified this view considerably ${ }^{4}$, as histological studies have revealed that the vestibular apparatus of the newborn animal is undifferentiated and therefore nonfunctional ${ }^{5,6}$. To investigate whether one of these mechanisms ${ }^{2,4}$ could account for the behaviour of the newborn quokka (Setonix brachyurus) we have observed parturition in this macropodid marsupial.

Female quokkas mate soon after giving birth and such animals often develop a blastocyst in the state of diapause in the uterus. Removal of the pouch young causes this blastocyst to resume development so that a birth occurs about 26 days later ${ }^{\tau}$. In March 1974 and 1975 pouch young were removed from a total of 14 quokkas obtained from a wild population on Rottnest Island, Western Australia. The animals were transferred to a controlled environment $22 \mathrm{~d}$ later, then observed continuously. In all, seven animals gave birth; four births were seen and one was recorded in detail on videotape.

Our observations of these births confirm those of Tyndale-Biscoe ${ }^{8}$. In spite of intensive antepartum grooming of the pouch and cloacal region, there is no evidence of a path made by the mother to facilitate the passage of the joey from the cloaca to the pouch. The mother's position during birth was such that the abdominal wall was almost vertical and the lower lip of the pouch pouted outwards. Observation of the actual entry of the joey into the pouch was difficult because of the stance of the mother but on one occasion the joey seemed merely to tumble in over the lip.

After a birth in 1974 the joey was retrieved as soon as it had reached the pouch. The mother was then held vertically, head up, and the joey was placed on the upper (anterior) lip of the pouch. During the next $3 \mathrm{~min}$ it climbed about $3 \mathrm{~cm}$ upwards away from the pouch. The mother was then turned upside down. The joey faltered and eventually turned completely around so that its head was again pointed upwards, towards the pouch. It then became entangled in the mother's fur and made no progress. When the mother was returned to the head up position the joey reversed its direction again and progressed away from the pouch. It was then removed from the mother's chest and replaced near the cloaca, whence it succeeded in making a second journey to the pouch.

On the occasion of the videotaped birth in 1975 the mother was removed from her cage and held almost vertical, with her right side slightly lower than her left, while the newborn joey was still making its initial journey to the pouch. This led to its direction changing slightly so that it passed by the pouch; it did not falter but continued to climb to the mother's chest, leaving a distinct path, about $1 \mathrm{~cm}$ deep, in the fur. The mother was then turned to the head down position and, as before, the joey slowly turned around, this time without becoming entangled in the fur, and made progress back towards the pouch. The joey was not handled during this experiment.

These observations suggested that the newborn quokka has a righting reflex; we found that it could also turn over when placed on its back. But older pouch young, up to the age of $65-70 \mathrm{~d}$, no longer retain this ability, and histological sections through the head of a newborn joey support the conclusion that the vestibular apparatus is undifferentiated $^{5,6}$. It seems to us that this transient righting reflex could be mediated by muscle stretch receptors, particularly in the neck.

These experiments confirm the negative geotropism of the newborn quokka and reveal no other mechanism directing its movement towards the pouch. In the second experiment, in particular, the joey passed within $1 \mathrm{~cm}$ of the pouch opening without hesitating in its upward climb and it is clear that chemotaxis can be discounted in this case.

We thank Professor A. R. Main for helpful discussions. Department of Organic Chemistry

\section{J. R. Cannon}

H. R. BAKKER

S. D. Bradshaw

Department of Zoology,

University of Western Australia, Nedlands, Western Australia

Department of Physiology,

I. R. MCDONALD

Monash University, Victoria, Australia

Received September 9; accepted November 13, 1975.

1 Tyndale-Biscoe, H., Life of Marsupials (Edward Arnold, London, 1973). 2 Frith, H. J., and Calaby, J. H., Kangaroos (Cheshire, Melbourne, 1969).

3 Hartman, C. G., Anat. Rec., 19, 251 (1920).

4 Hartman, C. G., Possums, ch. 13 (University of Texas Press, Austin, 1952) Larsell, O., McĆrady, E., Jr, and Zimmermann, A. A., J. comp. Neurol. 63, 95 (1935)

6 Langworthy, O. R., Am.J. Physiol., 74, 1 (1925); J. comp. Neurol., 46, 201 (1928). Shield, J. W., and Woolley, P., Nature, 188, 163 (1960).

8 Tyndale-Biscoe, C. H., thesis, Univ. Western Australia (1961).

\section{Impaired acquisition of a passive avoidance response after lesions induced in the locus coeruleus by 6-OH-dopamine}

Crow' ${ }^{1}$ and Kety ${ }^{2}$ have advanced the hypothesis that the fine network of noradrenaline-containing nerve terminals which innervates the cerebral cortex ${ }^{3}$ is a necessary component of the mechanism of learning. In particular, it is suggested that these neurones deliver a "results of action" signal which registers the successful outcome of a particular behavioural sequence. The noradrenaline released in the cortex is believed to interact with a transient synaptic change resulting from recent neural activity (the 'short-term trace'), to initiate the long term synaptic changes presumed to underlie learning. Various authors have suggested the existence of such a "confirming reaction", "results of action" , or "now print" mechanism. The diffuse distribution of noradrenergic terminals in the cerebral cortex would allow this system to deliver a generalised message of the type required. Ungersted $t^{7}$ has demonstrated histochemically that the cortical noradrenergic terminals originate from cell bodies of the nucleus locus coeruleus in the dorsal pontine tegmentum, and this has been confirmed in biochemical studies ${ }^{8,9}$. The concept of the coerulo-cortical noradrenergic system as a reinforcement pathway is supported by the observation that rats with electrodes in the region of the locus coeruleus can be trained to self stimulate ${ }^{10,11}$ and this behaviour is accompanied by increased noradrenaline turnover in the ipsilateral cortex ${ }^{12}$.

The prediction that bilateral lesions of the locus coeruleus would impair learning capacity ${ }^{1,2,13}$ has been tested in a runway $^{8}$ and a two-choice discrimination learning test ${ }^{14}$. 